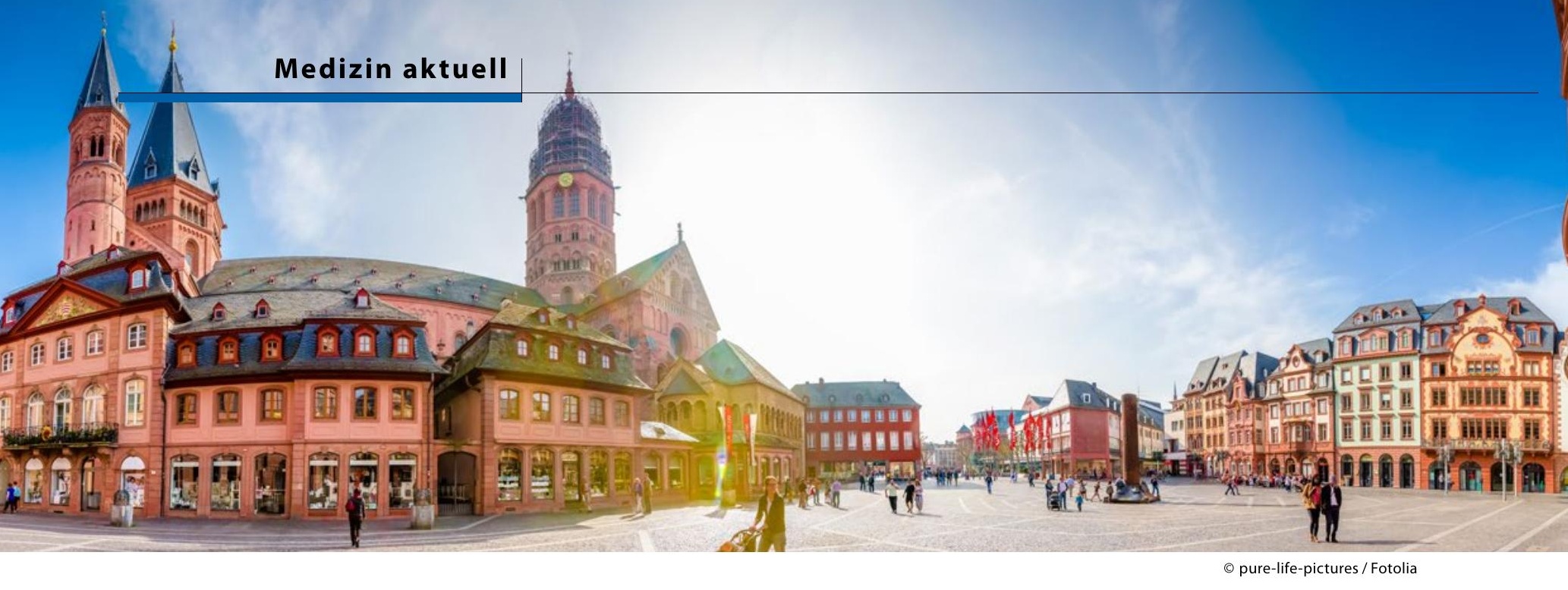

Neuro Update in Mainz

\title{
Neurologie auf dem neuesten Stand
}

\author{
Auch auf der diesjährigen Neuro-Update-Fortbildung in Mainz brachten die hochkarätigen Referenten die \\ Teilnehmer anhand aktueller Studienergebnisse binnen zwei Tagen auf den neuesten Stand im Fachgebiet.
}

\section{Neuromuskuläre Erkrankungen: Antikörper ermöglichen die Differenzierung}

\section{Die Diagnostik neuromuskulärer Erkrankungen ist heutzutage weit fortge- schritten und breit gefächert. Für einen guten Teil der Erkrankungen beste- hen auch medikamentöse oder symptomatische Therapieoptionen.}

\footnotetext{
E ine exakte klinische, genetische und

C labortechnische neuromuskuläre $\mathrm{Di}$ agnose vorausgesetzt, ist heute etwa die Hälfte aller neuromuskulären Erkrankungen (NME) behandelbar, sagte Professor Benedikt Schoser, Friedrich BaurInstitut der Universität München. Dies gelte vor allem für erworbene Erkrankungen. Voraussetzung für eine solche Erfolgsquote sei jedoch die Einbeziehung spezialisierter Zentren bei seltenen NME und die Anwendung aktueller symptomatischer Therapieformen. Standard für nahezu alle Myopathien ist ein abgestuftes körperliches Training.

Bei der Myasthenia gravis (MG) sind die generalisierte und die rein okuläre Form zu unterscheiden. Diagnostisch relevante Befunde sind Antikörper gegen Acetylcholinrezeptoren (AChR, bei bis zu $80 \%$ mit generalisierter und bis zu $50 \%$ mit okulärer $\mathrm{MG}$ ), gegen die muskelspezifische Kinase (MuSK, bei $10 \%$ ), gegen
}

das Lipoprotein receptor-related protein 4 (LRP4) sowie - bei initial rein okulärer Erkrankung - gegen Cortactin. Die drei letztgenannten Proteine bedingen die Stabilität der neuromuskulären Endplatte.

Therapeutisch sind Acetylcholinesterase-Hemmer sowie immunsuppressiv Steroide, Azathioprin, MTX oder intravenöse Immunglobuline (IVIG) meist effizient. Auch eine Thymektomie plus Prednison wirkt sich im Vergleich zu alleiniger Kortison-Gabe oft positiv auf den langfristigen klinischen Verlauf, die Symptomatik und die Zahl stationärer Einweisungen bei MG aus [Wolfe $\mathrm{G}$ et al. N Engl J Med 2016; 375: 511 -22], aber nicht bei MuSK-Antikörper-positiven Patienten. Eine Alternative zur Langzeittherapie therapierefraktärer Patienten mit AChR-Antikörpern ist Rituximab.

Vieldiskutiert sind bioptisch nachweisbare immunogen-nekrotisierende Myositiden (INM) nach hochdosierter
(80 mg/Tag) dauerhafter Statin-Einnahme. Bei diesen, meist älteren (> 50 Jahre) Patienten auftretenden INM finden sich oft Antikörper gegen Hydroxy-Methylglutaryl-CoA-Reduktase oder gegen SRP (Signal Recognition Particle) sowie häufig extrem hohe Werte der Kreatinkinase (CK). Schoser empfahl, als Basis vor Beginn einer solchen Therapie einmalig eine CK-Bestimmung. Therapeutische Konsequenzen sind das sofortige Absetzen des Statins sowie gegebenenfalls die Gabe von IVIG. Für therapierefraktäre Myositiden mit positivem Antikörpernachweis steht als Reservemedikament zudem Rituximab zur Verfügung.

Die McArdle-Myopathie, eine Glykogenspeichererkrankung mit dynamischen Symptomen als Folge mangelnder Energiebereitstellung, ist gut durch Ernährung und vor allem durch Training beeinflussbar. Im Gegensatz zu anderen Myopathien existieren hierfür detaillierte Empfehlungen [Nogales-Gadea $\mathrm{G}$ et al. Med Sci Sports Exerc 2016; 48: 673-9], die bei mindestens 150 Minuten wöchentlichem Training eine mehrere Jahre anhaltende Verbesserung der Krankheitsaktivität bewirken.

Dr. Andreas Häckel

Neuromuskuläre Erkrankungen (Professor Schoser). Neuro Update, Mainz, 4.3.2017 